SACKet, D. L.. Rosenberg, W. M. C., Gray, J. A. M., et al (1996) Evidence based medicine: what it is and what it isn't. British Medical Journal, 312, 71-72.

DAVID MARCHEVSKY, St Michael's Hospital, St Michael's Road, Warwick, Warwickshire CV34 $5 Q W$

\section{Providing a psychiatric service to liver transplant patients}

Sir: Mitchell et al (Psychiatric Bulletin. January 1997, 21, 6-9) give an interesting description of their work providing a psychiatric service to liver transplant patients at the Edinburgh Royal Infirmary. They argue that a psychiatric opinion should be sought in all cases of assessing suitability for liver transplantation. We have been considering our work with liver transplant patients at the Bristol Royal Infirmary.

By assessing all transplant patients preoperatively, psychiatrists are drawn into the complex and largely opaque process of the allocation of scarce resources. We have concerns about the consequences of diagnosing a mental illness in a patient en route to liver transplantation. Mitchell et al considered one patient too depressed to cope with the operation and advised against transplantation. This raises some difficult ethical questions for psychiatrists. Who can and should allocate scarce resources? On what grounds should these choices be made? Should we participate in the denial of a patient in endstage liver failure the only real hope of survival?

Surman (1989) describes successful outcomes after transplant surgery for a number of patients with psychosocial problems. Rather than assessing all patients for suitability for transplant surgery, we advocate concentrating resources on the few patients who need specialist support through the stress of the procedure.

SURMaN, O. S. (1989) Psychiatric aspects of organ transplantation. American Joumal of Psychiatry. 146. 972-982.

ROGER DENNY, Kingswood Community Mental Health Team, Cossham Hospital, Kingswood, Bristol BS15 ILF; JAN CRIBB and JONATHAN EVANS, Barrow Hospital, Barrow Gurney. Bristol BS19 3SG

\section{Section 3 - hidden consequences}

Sir: Detention under Section 3 of the Mental Health Act may have consequences not only for the patient, but also for relatives, staff and other patients. Consider an elderly, confused, informal patient awaiting nursing home placement. Having wandered and been returned with some coercion, Section 5(4) was implemented, because he was on a psychiatric ward. Successive Sections resulted, although it was paradoxical that a man fit to leave hospital was being detained.

Paperwork, resulting solely from use of the Act, can be quantified. Section 5(4) led to four forms and reports (six copies); 5(2) generated nine forms, rights leaflets, etc. (two copies): Section 2 led to 47 forms, pages of reports to managers and tribunal, etc. (135 copies); Section 3 produced 54 pages of reports, appeal decisions, leave forms, Form 39, MHAC I, etc. ( 149 copies). This gave a total in this complicated, but not unusual, case of 114 original pages and 292 copies. Aftercare (Section 117) paperwork is not included.

Financial considerations are most relevant. He was able to afford his fees - already agreed. However, Section 3 leads to Section 117 aftercare when fees (over $£ 300$ a week) are fully met by the local authority - indefinitely, since dementia does not improve! A further apparent advantage is speed of discharge as priority appears to be given to patients "detained against their will" over those "informally waiting" in hospital. Other patients may feel disadvantaged. The additional costs of full Section 117 meetings in nursing homes are not insignificant. Pressure not to discharge from Section 117 is felt, since to do so passes the full bill to patient and family.

The impression gained is that articulate, financially successful men tend not to accept confinement to a ward. Section then ensues, and fees are met. Those with more limited financial resources may be more compliant, and their relatively smaller savings are used for their care. Perhaps knowledgeable families realise the benefits Section 3 brings! If all demented people were deemed unable to consent to care, all might currently benefit from Section 3 , to the disadvantage of non-demented nursing home applicants. Should the financial benefits of Section 3 status be retrospectively paid? Public funds should not be used for people solely because they happen to have been detained under Section 3, a major procedure which can be, in this group of patients, surprisingly arbitrary in application.

M. T. MALCOLM, M. N. LANCEFIELD and C. $\mathrm{H}$. WARRINER, Clatterbridge Hospital, Bebington, Wirral, Merseyside L63 4JY 